\title{
PARADOXICAL POST-COUPLING COURTSHIP \\ IN HIMANTIGERA NIGRIFEMORATA (DIPTERA, STRATIOMYIDAE)
}

\author{
By William G. Eberhard \\ SMithsonian Tropical Research InSTITUTE \\ AND \\ Escuela de Biologła, Universidad de Costa Rica \\ Ciudad Universitaria, Costa Rica
}

If the function of male courtship behavior is to inform the female of a male's species identity, or to otherwise induce her to allow mating to occur, then continuation of courtship after copulation has begun would seem to be non-functional. Such post-coupling courtship does occur in some species, however (see summary in Eberhard 1985, also Loher and Rence 1978, Speith 1984, Longair et al. 1987, Goldsmith 1987, Mora 1987, Wcislo in prep.). It might be argued that post-coupling courtship is selectively trivial, perhaps a sort of overflow that results from high excitement levels in males. On the other hand, male courtship behavior could be selectively important, serving to induce females to perform key additional reproductive processes such as allowing copulation to proceed until semen transfer is complete, transporting sperm to storage sites, ovipositing, rejecting additional suitors, etc. The possibility that such "cryptic female choice" (Thornhill 1983) occurs after copulation begins has substantial theoretical significance, and a general theory explaining the rapid and divergent evolution of animal genitalia (Eberhard 1985) relies on the supposition that post-coupling courtship is often performed by the male's genitalia. This paper reports observations suggesting that post-coupling female choice is indeed selectively important in the stratiomyid fly Himantigera nigrifemorata (Macquart).

\section{Materials AND Methods}

All flies were observed between 10:00 and 14:00 on sunny or partly cloudy days between June and September 1987 in early second growth near San Antonio de Escazù, San Josè Province, Costa Rica. Small piles of recently cut weedy vegetation were used to attract flies. Fifteen copulating pairs were observed. In some 
cases a screen was laid over the pile of vegetation to make it easier to spot pairs before they became hidden in the vegetation. Video recordings of four copulating pairs were analyzed frame by frame (30 frames/sec.); two other pairs were observed with lenses giving 4-8 $\times$ magnification.

Flies were raised from a pile of cut vegetation which had been left on the ground for 3 days, then placed in a gunny sack with a clear plastic bag attached to its open end. Voucher specimens are deposited in the U.S. National Museum, Washington, DC 20560.

\section{RESULTS}

Male flies began to arrive within 5-10 minutes after the vegetation was cut, and often accumulated in large numbers (up to more than 30 per square meter) within 30 minutes. They alternately perched on the vegetation, and flew, often in short darting flights toward other flies, producing brief collisions and clashes, or short pursuits. They did not defend territories, but gradually drifted over the cut vegetation and nearby plants. Occasionally they hit and momentarily seized other males that were either perched or, more rarely, in flight. On four occasions a male bumped briefly against a mating pair resting on the vegetation, but none of the pairs separated as a result. Flies collected in two aggregations about one hour after vegetation was cut were nearly all males ( 31 of 32 and 41 of 41 ).

I saw the initial stages of pair formation on two occasions. The male seized the female in the air $1-2 \mathrm{~cm}$ over the vegetation and the pair immeditely landed, with the male on the female's dorsum. The male immediately made genital contact as he scrambled briefly with his front legs on the female's head. Then he rested quietly on her dorsum for $<5$ seconds before beginning a series of courtship movements. Although the durations and sequences of the movements varied somewhat, at least three types of behavior were recognizable.

\section{Tapping}

A male tapped by raising his front legs, usually holding them briefly immobile as they projected more or less forward over the female's head, then "winding up" by bringing them sharply back and upward over his head, and then "swinging" them sharply downward over the female's head with a whipping motion (Figs. 1 and 2). The leg usually (perhaps always) stopped just short of hitting the 


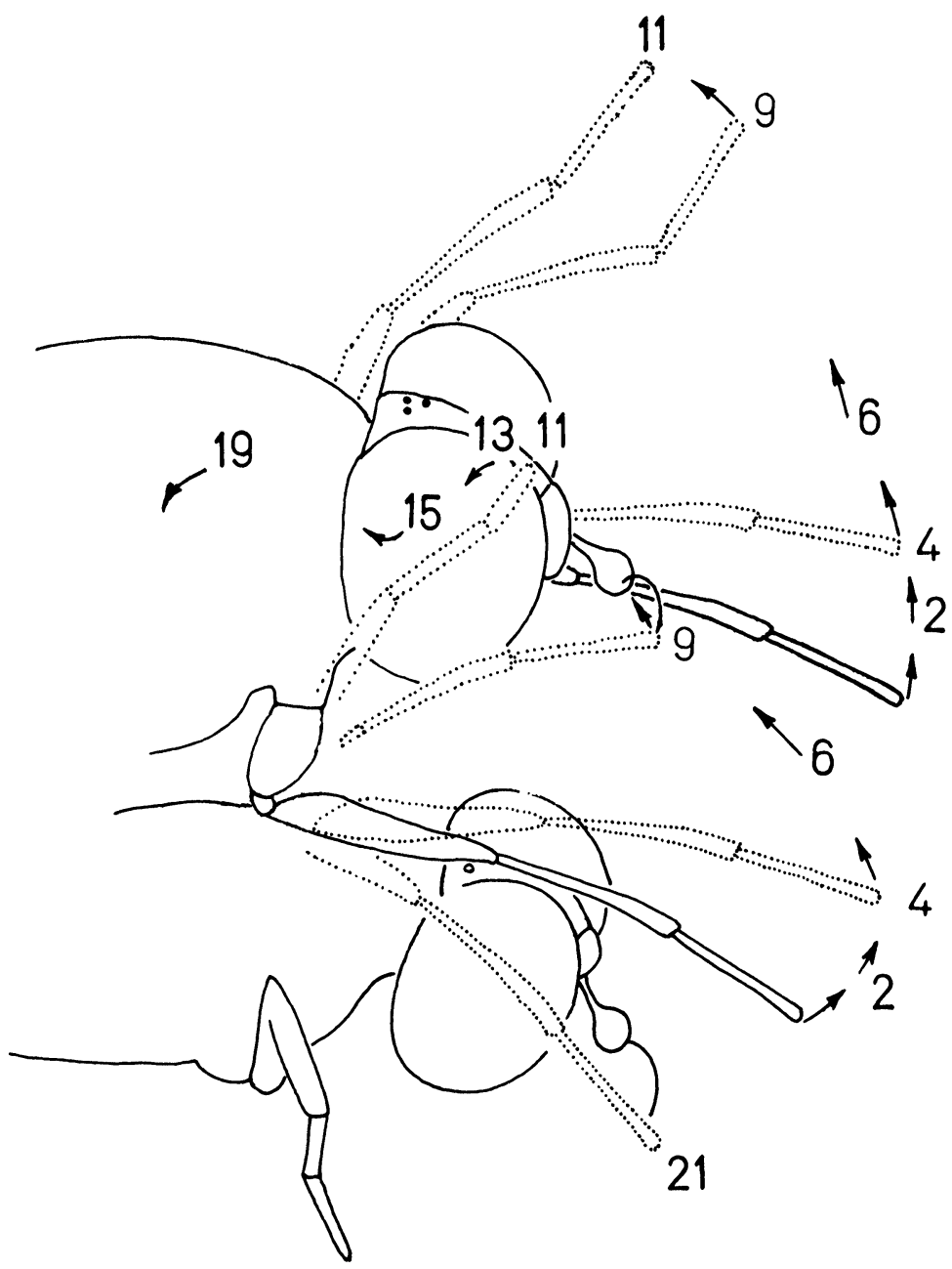

Fig. 1. Initiation of tapping movements of front legs of a copulating male $\boldsymbol{H}$. nigrifemorata seen from the side and slightly above (drawn from tracings from a video recording). Numbers and dotted lines indicate number of frames (30 frames/ sec.) after starting leg position (solid lines) and positions of legs at these times. Both legs were raised simultaneously until they were over the male's head (frame 11); then, after a brief pause, the right leg was brought further back (frames 13-19), then tapped briskly downward (frame 21). It was not possible to determine from the videotape whether the tarsus contacted the female's arista. 
female's eye (Fig. 1); in at least some cases (probably often, but certainly not always) the leg hit against the arista of the female's antenna.

Tapping occurred in short bouts averaging 5.0, 4.6, 3.8 and 4.3 taps/bout in four different pairs (range 1-17, coeff. of variation averaged $56 \%$ in the four pairs). The average times between bouts for four pairs were 2.6, 3.5, 4.2, and 4.6 sec. (range 1.1-14.7, coeff. of variation averaged $56 \%$ ). Usually the male held both front legs directed more or less anteriorly over the female's head (solid lines in Figs. 1 and 2) during pauses between bouts. Bouts nearly always ( 88 of 95 cases) began with the male raising both front legs simultaneously (Fig. 1). Then one leg wound up and swung, and, as soon as it came to rest, the other leg wound up and swung. From then on tapping was nearly always strictly with alternate legs (205 of 207 cases; in one case both legs hit simultaneously, and in the other the same leg hit twice in succession). The leg not being swung was held immobile while the other was lifted and swung. Average times between the downstrokes of taps were $.41, .43, .44$, and .49 sec. (range $0-1.5$, coeff. of variation averaged $41 \%$ ). Usually (40 of 50 cases) the interval between the first two taps was shorter than that between the second and third.

\section{Twitching}

Twitching occurred between bouts of tapping when both of the male's front legs had been immobile and apparently in contact with the female's aristae. Twitching probably caused deflections of the aristae. To the naked eye the movements of the legs resembled rubbing, but the videotapes showed very rapid, brief (usually only 1-2 frames), and variable movements. The legs moved dorsally, ventrally, or laterally to either side. Sometimes both front legs were twitched simultaneously, while in others only one was moved. More than a single twitch was performed in 9 of 20 pauses with twitches (maximum was 6). Individual males differed in their tendencies to twitch: three flies twitched at least once during 20 of 56 pauses, while the fourth did not twitch in any of 20 pauses $(p<.05$ with Chi-Squared Test).

\section{Rocking and scrabbling}

Scrabbling involved movements of the male's body and all of his legs. The front and middle legs rubbed erratically on the female's head and body, and his body moved short distances both laterally and forward and backward, also in an erratic pattern. 


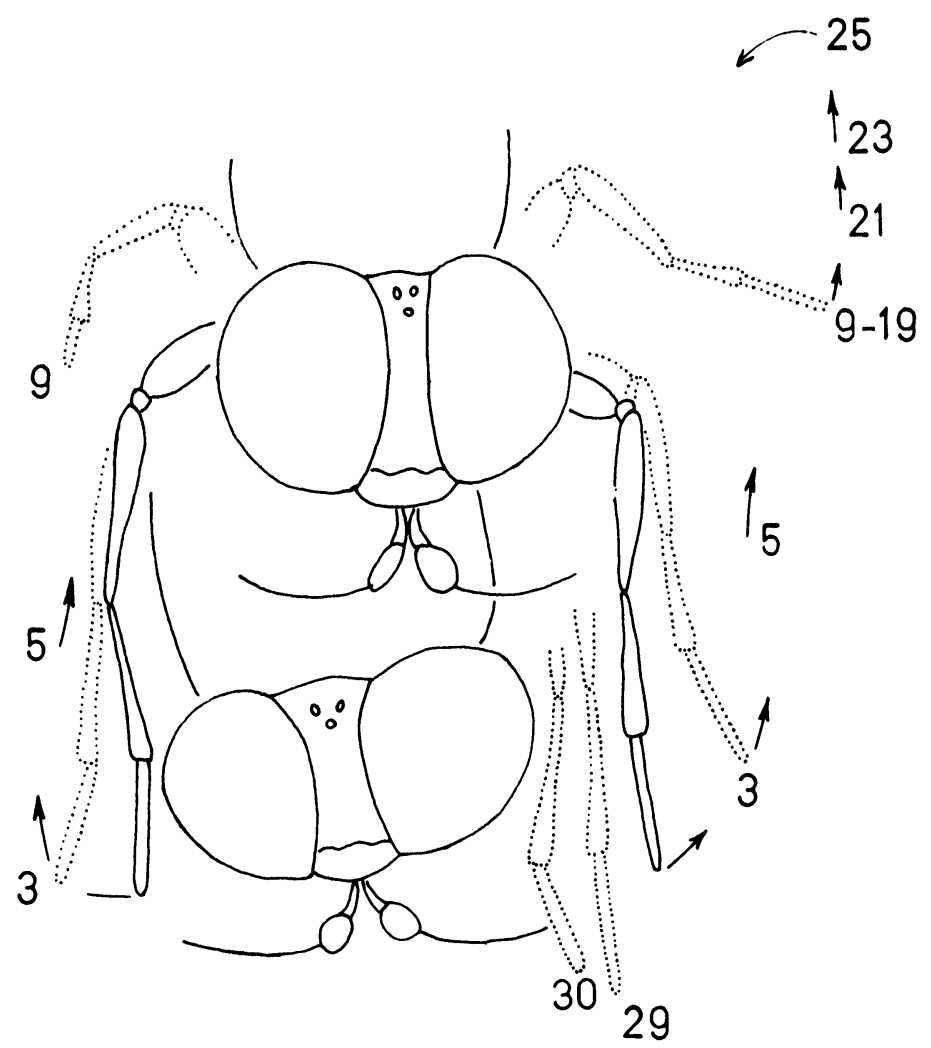

Fig. 2. Initiation of tapping movements by a different male $\boldsymbol{H}$. nigrifemorata seen from above and in front (drawn from tracings from a video recording). Numbers and dotted lines indicate number of frames after starting leg position (solid lines) and positions of legs at these times. After both legs were raised simultaneously to point upward over the male's head (frame 9), the left leg was held immobile (9-19) while the right leg swung back and down (not shown); then the left leg was swung back (21-25) and then down (25), then moved slightly to the side (30). It was not possible to determine from the videotape whether the tarsus contacted the female's arista.

Often the joined tips of the male and female abdomens were raised and lowered repeatedly during or just before or after scrabbling. The female rocked forward when her abdomen was lifted. Apparently these movements were caused by the male rather than the female, since in two pairs observed after their genitalia became uncoupled, the male's scrabbling movements were often accompanied by brisk lifts of his abdomen which probably correspond to the 
rocking movements observed in pairs (a screen prevented these females from walking down into the vegetation; genital contact terminated after about two minutes but the male remained on the female and continued to execute courting movements). The dorsal and forward force generated during male lifting movements probably came from his hind legs, which were usually braced on the substrate. Probably the effect of the rocking movements was to drag the female slightly forward by her genitalia.

In each of the ten courtship sequences in which I observed termination, the female walked down into the vegetation. In all but one case, when the male was scraped off by protruding vegetation, the male was still riding on her dorsum when she disappeared. The dislodged male hovered for several seconds about $5 \mathrm{~cm}$ over the site where the female had disappeared, then flew away. Females probably oviposited when they walked down into the pile of vegetation, as flies were raised ( 14 males and 15 females) from a pile into which mated females had disappeared.

\section{Discussion}

There are several reasons for classifying the behavior of copulating males as courtship. The patterns were relatively stereotyped, both in form and, to a lesser extent, in sequence; the males' movements undoubtedly caused stimulation of the female; they were performed consistently in male-female interactions and never in other contexts; and they were unlikely to have any other functions for the males. None of the movements described was performed before genitalic coupling was achieved, while all males made at least some of the movements soon after coupling began. It is unlikely that the post-coupling male behaviors were some sort of selectively irrelevant "overflow" courtship, because they never began until after coupling had occurred.

Demonstration that male $\boldsymbol{H}$. nigrifemorata only court females after achieving genitalic coupling supports the idea that postcoupling courtship in this and, by extension, other species with post-coupling courtship can be selectively significant. This demonstration of the importance of cryptic female choice is, in turn, in accord with the argument that male genitalia are often selected to perform "internal courtship" after intromission has begun (Eberhard 1985). 
It is not certain which female post-coupling reproductive process(es) male $\boldsymbol{H}$. nigrifemorata were attempting to induce. Rocking behavior may serve to start the female walking, causing her to move away from other males down into the vegetation.

Strictly post-coupling courtship involving body parts other than genitalia also occurs in the bee Centris pallida (Alcock and Buchmann 1985), the sphecid wasp Glenostictia satan (Longair et al. 1987), another stratiomyid, Merosargus stamineus (Fabricius) (pers. obs.), and perhaps the phorid fly Megaselia sp. (W. Wcislo in prep.). It may be significant that in all of these species males swarm (or, in the case of the phorid, are at least common) at sites where receptive females occur, and compete to grab females before other males do so. Males in such swarms may have to postpone courtship until they have the female "in hand" and protected from the advances of other males. That females consistently allow immediate coupling in these species argues against the supposed need for females to make males prove their species identity with elaborate courtships before they allow them to copulate.

\section{SUMMARY}

Males of Himantigera nigrifemorata consistently courted females, but only after they had achieved genitalic coupling. Courtship consisted of a complex series of partially stereotyped behaviors. Such post-intromission courtship is in accord with the idea that "cryptic female choice" is selectively important.

\section{ACKNOWLEDGMENTS}

I thank Norman Woodley for kindly identifying the flies and providing background information. Bill Wcislo and Mary Jane West-Eberhard made helpful comments on the manuscript, and the Vicerrectorìa de Investigaciòn of the Universidad de Costa Rica provided financial support.

\section{REFERENCES}

Alcock, J. And S. Buchmann. 1985. The significance of post-insemination display by male Centris pallida (Hymenoptera: Anthophoridae). Z. Tierpsychol.

Eberhard, W. G. 1985. Sexual selection and animal genitalia. Harvard Univ. Press, Cambridge. 
GolDSMITH, S. K. 1987. Resource distribution and its effect on the mating system of a longhorned beetle, Perarthrus linseyi (Coleoptera: Cerambycidae). Oecol. (Berlin) 73: 317-320.

LOHER, W. AND B. RENCE. 1978. The mating behavior of Teleogryllus commodus (Walker) and its central and peripheral control. Z. Tierpsychol. 46: 225-259.

Longair, R. W., J. H. CANE, AND L. Elliot. 1987. Male competition and mating behavior within mating aggregations of Glenostictia satan Gillaspy (Hymenoptera: Sphecidae). J. Kans. Entomol. Soc. 60: 264-272.

MorA, G. 1987. Male egg-guarding behavior in the Neotropical harvestman, Zygopachylus albimarginalis (Opiliones: Gonyleptidae). MS thesis Univ. Florida.

Speith, H. T. 1984. Courtship behaviors of the Hawaiian picture-winged Drosophila. Univ. Cal. Pub. Entomol. 103: 1-92.

Thornhill, R. 1983. Cryptic female choice and its implications in the scorpionfly Harpobittacus nigriceps. Am. Nat. 122: 765-788.

Wcislo, W. in prep. Natural history of a fly, Megaselia sp. (Diptera: Phoridae), in the nests of a solitary bee, Lasioglossum sp. (Hymenoptera: Halictidae) 

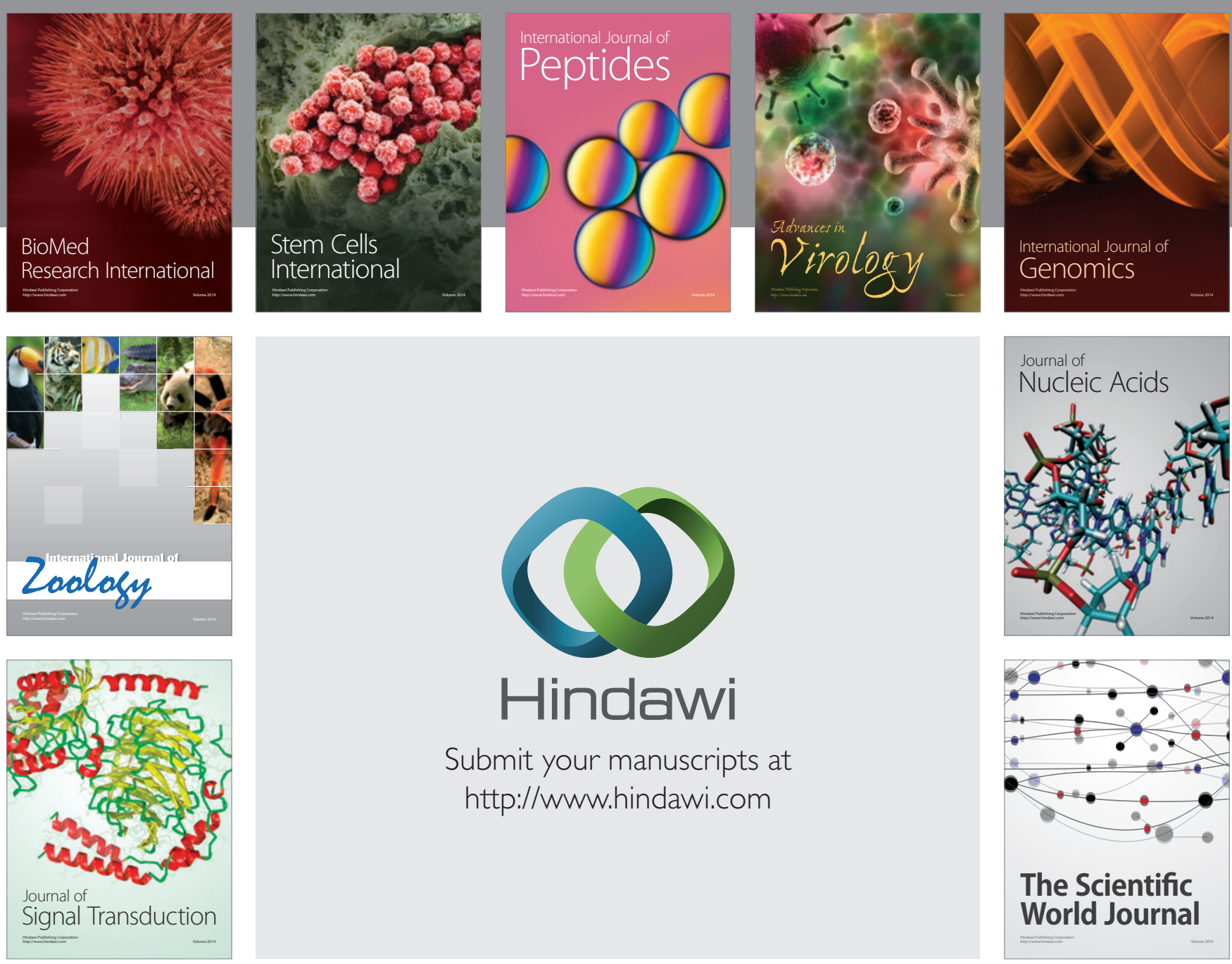

Submit your manuscripts at

http://www.hindawi.com
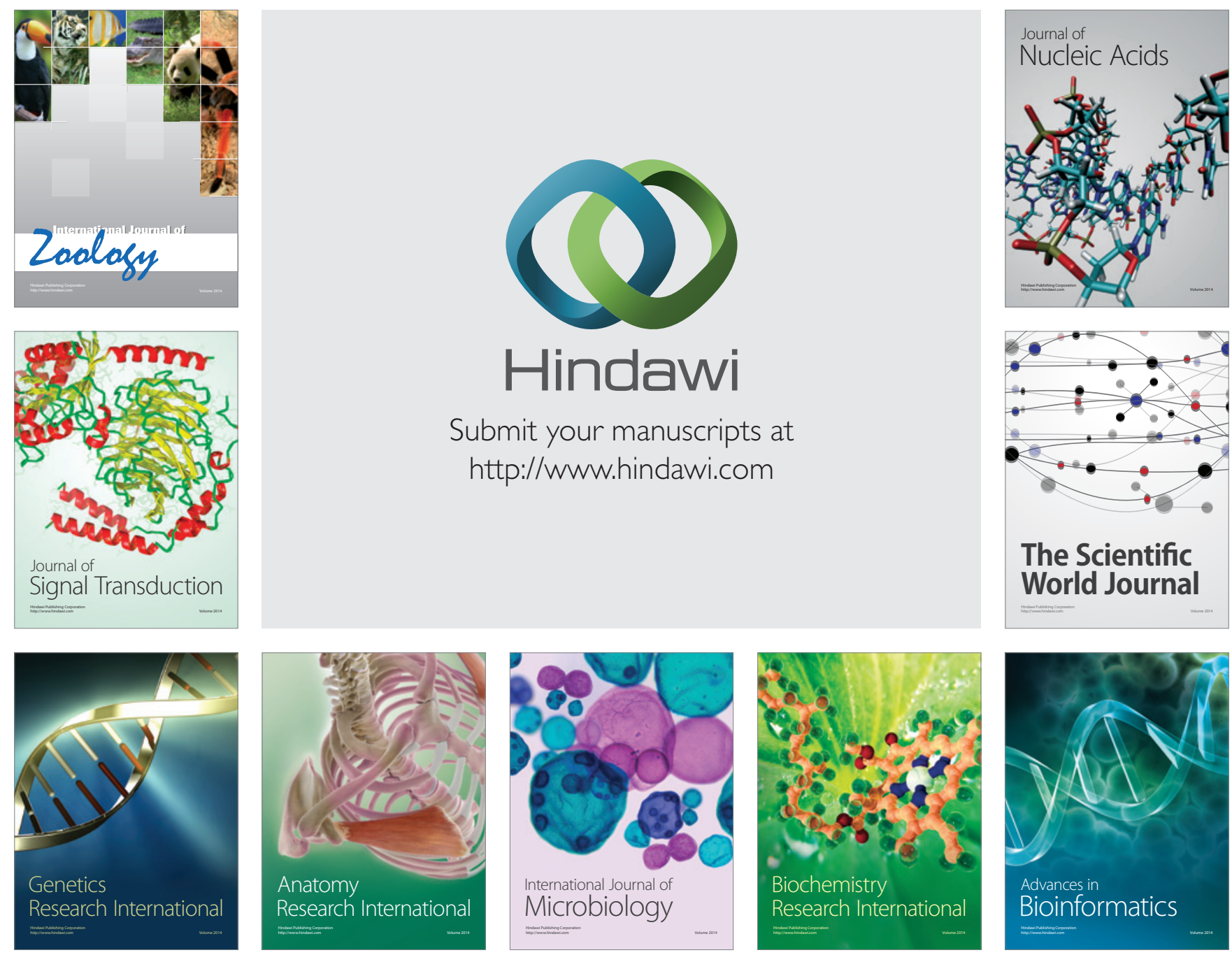

The Scientific World Journal
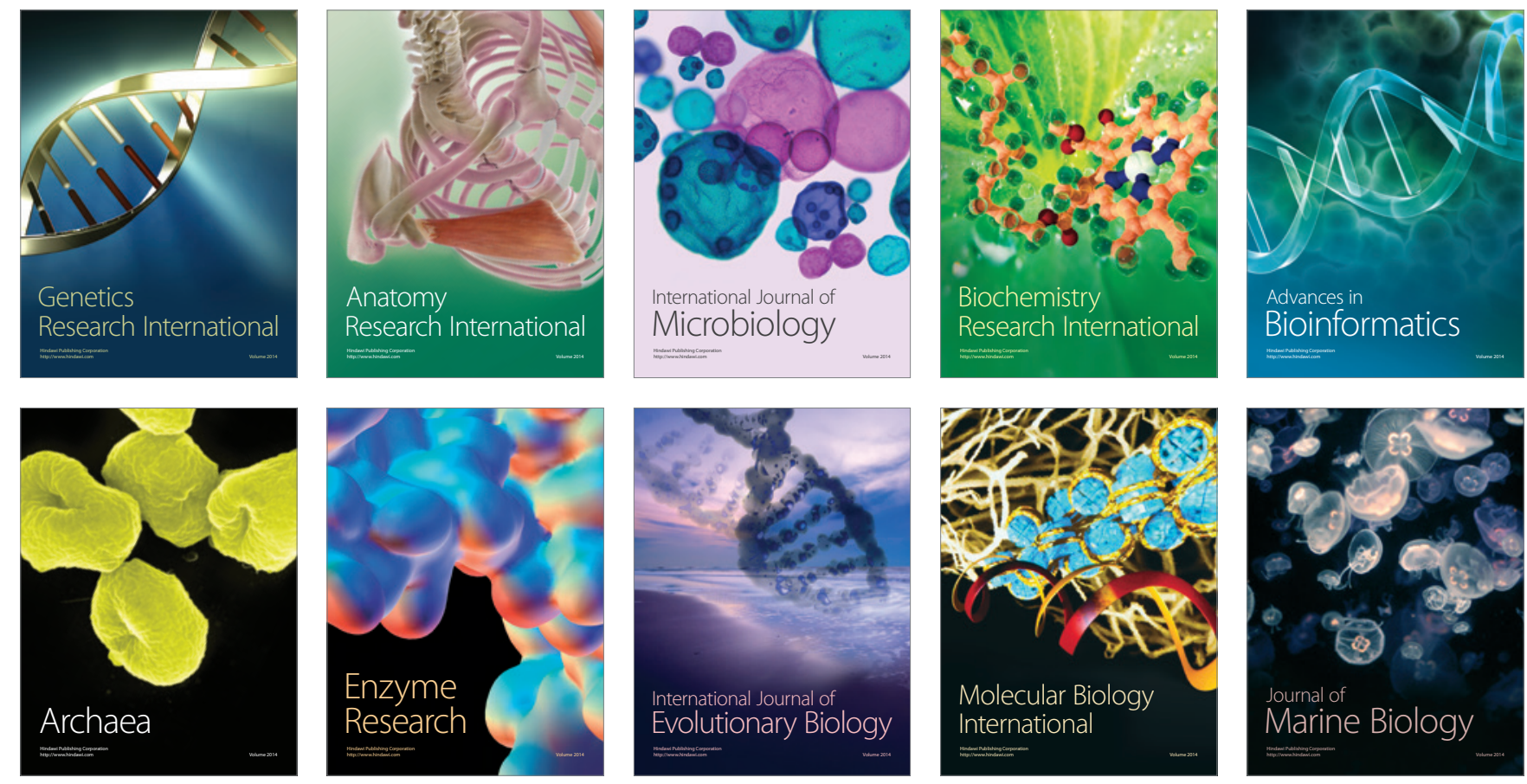